\title{
A Critical Discourse Analysis of Selected Utterances of State Actors on the 2019 Xenophobic Attacks on Nigerians in South Africa
}

\author{
Damilola Oluseyi Fafiyebi \\ damilola.fafiyebi@eksu.edu.ng \\ Department of English and Literary Studies, Ekiti State University, NIGERIA
}

\begin{abstract}
The study examined the discourse strategies employed by state actors in expressing their views on the 2019 xenophobic attack in South Africa. The objective is to examine how this group of people explores the provisions of critical discourse to shape and pattern their communicative intention. The data employed for the study were sourced from selected online media sources between September and November 2019. The study employed the Critical Discourse Analysis (CDA) approach with a particular focus on the Discourse Historical Approach framework proposed by Wodak (2001) as its theoretical springboard. The study established that different state actors from each of the countries under scrutiny engage in positive self and negative others presentation. This showed that from their discourses, it can be deduced that the state actors were all out to launder the image of their respective countries on the one hand and that of the kith and kin on the other hand.
\end{abstract}

Article

information

Keywords: xenophobia; state actors; critical discourse analysis; discourse strategies

\section{DOI: 10.24071/joll.v20i2.2394}

Available at https://e-journal.usd.ac.id/index.php/JOLL/index

This work is licensed under a Creative Commons Attribution-ShareAlike 4.0 International License.

\section{Introduction}

The word 'xenophobia' is derived from a combination of two ancient Greek lexical items 'xeno' meaning strange and 'phobos' which means fear. Thus, xenophobia can be described as a strange feeling of fear resulting in the breakdown of law and order. It is an act that tends to cause human beings to behave irrationally. The phenomenon was first manifested in the denigration of foreigners as barbarians by Greek citizens. The Greek were of the belief that other people and culture were inferior to the Greek way of life and that other nationals were only fit and meant to be slaves. Cooperation, as well as cross-cultural interchange of ideas, has always been the order in every normal human assembly. The encyclopedia Britannica also described xenophobia as an extreme fear or apathy towards strangers. Xenophobia as an antisocial act is characterized by a negative perception or attitude towards strangers. It is a kind of emotional and psychological disorder that makes people feel seriously unsafe in the midst of strangers. 
This feeling can be described as the resultant effect of a feeling of inferiority. Kollapan (1999, p. 40) argued that xenophobia as a phenomenon comes with unimaginable violence and physical abuse. It can be described as an anti-social tendency in which groups of people constitute a threat to the existence or survival of others. Xenophobia as an anti-social act, especially as witnessed in South Africa recently has left tears and destruction in its trail. He further explained xenophobia as being more than an attitude but as a practice and an activity. A major feature of the recent xenophobic attack against foreigners in South Africa is that it was not just targeted at foreigners. It was masterminded by black South Africans against 'black' foreigners. Therefore, looking at this social menace from a scholarly perspective, we can explain xenophobia as a political struggle for the attention of the state. It is a fight over who has the right to enjoy the perks of statehood. It is triggered by the feeling that 'strangers' are benefiting more from the state at the detriment of the citizens. Harris (2000, p. 50) identified three hypotheses that surround xenophobia. He identified the scapegoating hypothesis, the isolation hypothesis, and the bio-cultural hypothesis.

The scapegoating hypothesis situates xenophobia in the context of social changes. Under this hypothesis, hostility towards foreign nationals is fueled by the struggle for limited resources and limited employment opportunities. The resources include basic amenities like housing, healthcare, and education. It is a reactionary tendency that makes the people transfer their frustration to foreigners. This frustration is a result of failed expectations from the state. This is premised on the fact that successive governments have made certain promises to the people and have not been able to fulfill those promises. These failed expectations then open the eye of the masses to the unequal distribution of state resources, which in turn triggers violence. The resulting violence is, however, targeted at foreigners because they are considered as the main competitors for the available resources. This is notwithstanding the fact that these foreigners are in the minority because Morris (1998) affirmed that if the majority finds itself in a perilous economic situation, there is a tendency for it to feel threatened by the minorities especially if they are foreigners. The scapegoating hypothesis therefore concludes that foreigners are blamed and made the scapegoats for the woes of the citizens thereby becoming easy targets of the citizens' fierce anger, hostility and aggression. The isolation hypothesis is based on the view that a group of people with no positive history of incorporating or interrelating with strangers may find it difficult to sustain any interpersonal relationship.

The isolation hypothesis advanced by Harris (2000, p. 52) describes the South African xenophobic experience as fallout of the people's apartheid experience. Morris (1998) argued that the apartheid experience in a way segregated South Africans from the rest of the world, most especially Africa. During the apartheid era, South Africa had to contend with various international sanctions that ended up isolating them from the rest of the world. The isolation hypothesis suggests that for the South African, the world constitutes the unknown. It is, therefore, instructive that South Africans are finding it difficult to accommodate foreigners in their country. The bio-cultural hypothesis can be summarised as a prelude for the scapegoating hypothesis. Morris argues that foreigners are singled out for xenophobic attacks as a result of their cultural differences, which are immediately noticeable. It is noteworthy to say that Nigerians become easy targets here because of their language, physique, and dressing. In terms of language, Nigerians are often unable to speak any South African indigenous languages, for dressing; they have a unique dress style that marks them out as Nigerians even among the rest of the world while their hairstyle and intonation also tend to give them away. This hypothesis can be supported by the use of the identification method employed by the internal tracing unit of the South African Police. This unit is saddled with the responsibility of finding out if an offender is a South African native or not.

In carrying out its duties, the unit identifies biological and cultural features such as hairstyles, accents, intonation, vaccination marks, dress and individual physical appearances are interpreted as signifiers. They 
point out differences with which foreigners are immediately identified. Attempting a critical discourse analysis of state actors in the xenophobic attacks against Nigerians in South Africa is an attempt to examine the discourse patterns and strategies employed by state actors as major players in shaping and influencing public opinion.

Sociolinguistics is commonly regarded as a field of language inquiry that investigates the language usage of particular human groups and relies on data sources and analytical paradigms quite distinct from those employed by core linguists (Gumperz 1982, p. 9). Critical discourse analysis as a branch of sociolinguistic study is premised on the belief that text and talk are important tools for maintaining and granting legitimacy to the oppressive tendencies and class inequalities that are a feature of the human society. As expressed by Halliday and Hassan (1989), language is meta-functional; it serves textual, ideational and interpersonal purposes. This means that language is a logical combination of a lexico-grammatical system that has been employed to perform a particular function. In other words, language is a process that employs linguistic properties to produce a piece of meaningful discourse. Halliday and Hassan (1989) opined that for us to be able to interrogate and comprehend a communicative event, there is the need to be able to interpret the text in terms of its meta-functions. CDA considers how language, either spoken or written enacts social, cultural, and ideological perspectives (Gee 2005:1). Discourse analysts therefore look for answers to the question of language use by examining social, economic and political discourses. Critical discourse analysis does not only study text and talk but also the context that gives rise to the discourse under consideration. CDA is therefore considered a tool for disclosing the discursive nature of many modern day social, political, economic, and cultural transformations. As discourse analysts, we should be able to understand the context and the participants involved in the discourse and the period of the discourse. Since discourse is a kind of exchange between participants, we should understand the role of and relationship between each of the participants. We are equally expected to understand the function or the objectives of the discourse under study. Language performs three important functions: the ideational function of constructing representations of the world, the interpersonal function of constituting social interactions, and the textual function of creating cohesively structured texts and communicative events. This no doubt supplies the needed ingredients for critical discourse analysis, which engages both with the way language is used to construct and disseminate discourses.

CDA is a type of discourse analytical research that is interested in studying the way social power abuse, dominance, and inequality are reflected, produced, reproduced, and resisted by the instrument of text and talk in the social and political context Fairclough and Wodak (1997, p. 80). Discourse plays an important role in the expression and reproduction of institutional, personal, social, economic or political ideologies. Critical discourse analysis seeks to take a standpoint with the aim of understanding, exposing and resisting social inequality (vanDijk 1997, p. 10). Fairclough \& Wodak (2002, p. 95) argued that the aim of CDA is to provide a critical perspective for human communication through conversation analysis, rhetoric, stylistics, sociolinguistics, ethnography, or media discourse analysis. CDA as a linguistic craft, therefore, becomes necessary because the analysts are more or less aware of their roles not just as passive members of the society but as valuable linguistic surgeons who have the duty of interpreting language use based on the context of usage. CDA is equally of the view that there is a strong link between language and society and that such a connection should not be ignored but annexed for appropriate understanding and interpretation of language use. It is agreed that CDA subsumes a variety of approaches towards providing a social and theoretical analysis of discourse (Van Dijk, 2007).

In the light of the foregoing, the present study will adopt Wodak's discourse historical model as its analytical framework. This model is apt for this study because in the words of Wodak and Meyer (2001), it is designed to address discriminatory and political discourses in which language users tend to 
argue for or against particular views, concept or ideas. This is supported by the claim that the discourse historical method was employed in a study that examined discrimination against immigrants from Romania and in a study on the discourse on nation and national identity in Austria (Wodak et al. 1999). The discourse historical approach, as applied in the studies under reference, suggests that discourses on national issues and national identities normally employ four different macro strategies: constructive strategy, preservative strategy, transformative strategy, and destructive strategy. The constructive strategy creates national identities, views, and beliefs. The preservative strategy is deployed in consolidating the views already created while the transformative strategy aims at changing national identities. The destructive strategy seeks to dismantle national identities in the mind of language receivers. Based on the foregoing, the discourse historical model seeks to answer five important questions that are the heartbeat of the model. They are listed as follows:

a) How are discourse participants, concepts, institutions referred to linguistically?

b) What are the qualities, traits that are attributed to the identified individual?

c) What are the means through which arguments and argumentations are constructed to justify the discrimination, victimisation, oppression of the other group?

d) From what point of view or perspectives are the attributes, discriminations and oppression expressed

e) Are the respective utterances employed implied, stated indirectly, intensified or mitigated by means of polite utterances?

According to Wodak and Meyer (2001), these questions are specifically designed to unravel the discursive strategies employed in discourse. As expressed by the questions highlighted above, the discourse historical model seeks to answer questions regarding the nomination or referential terms, presentation of discourse participants, argument construction, discourse framing as well as the mitigating force employed in a piece of discourse.
Ademilokun (2018, p. 165) explained nomination as the discursive construction of social actors, objects, processes and actions. It is the presentation and representation of participants, events, individuals or situations that embody a piece of discourse. It may be represented with nominal phrases, pronominals, verbs and adjectives. It is the referential representation or categorization of discourse participants as in-group or outgroup participants. Joseph (2006, p. 345) explained that this representation is carried out through personalization or depersonalization of individuals or groups by means of descriptive metaphors and other figures of speech. Arthemis \& Monika (2010, p. 15) says that nominal items can either be referential or argumentative. They explain that while referential nominal elements are deployed in producing subjects that possess certain attributes, argumentative nominal elements are deployed in expressing the implication of the attributes of the subject. Joseph (2006:345) describes nominalisation as a discourse strategy employed to create identity. He opines that speakers and writers single out individuals, nations or concepts as important discourse features. Nominalisations is inseparable from language because it assigns names, labels and other forms of linguistic identity to discourse participants. Discourse inquiry into nominalisation is concerned with how the meanings of utterances are interpreted, not just following idealized word senses and rules of syntax but in the context of who is addressing whom in what situation and how speakers themselves are read. Nominalisation, therefore, explains the personality construct conveyed by the speaker and interpreted by the addressee.

In a view expressed by Reisigl and Wodak (2009, p. 90), predication is concerned with the positive or negative qualification of all the elements that make up a piece of discourse. Predication is concerned with labeling social actors either positively or negatively. It is employed with the aim of passing appreciative or non-appreciative comments on objects, phenomena, processes, and actions in a discourse. It is often done by evaluating the attributes of the target discourse actor(s). 
Argumentation, as a general notion, is concerned with the methodological presentation of our reasoning. Specifically, it is interested in the process of arguing in favour of, or against, a point of view, a course of action or an opinion. Ademilokun (2018, p. 160) described argumentation as the effort to provide justification or condemnation for stated claims. Argumentation is often generated from the topic and tends to provide the link between the discourse theme with the identification of particular subject and the conclusion (Ademilokun 2018, p. 161). This examines the means through which discourse participants justify the exploitation, exclusion, discrimination or inclusion of others as the case may be. Amossy (2018, p. 262) explained that the main objective of argumentation is to disclose the mechanisms and internal logic of situated discourse through the way it constructs patterns of reasoning and puts them into words in a given generic and institutional framework. Practically, it unveils the way underlying arguments and argument schemes are embedded into words in order to act upon an audience, orient collective decisions and action, oppose conflicting stances, or simply reinforce pre-existing choices and points of view.

Discourse framing is the expression of the viewpoints of discourse participants. Wodak and Meyer (2001) opines that framing focuses on the perspective through which the arguments making up a discourse are constructed. This is achieved through reporting, narrating or quoting events or utterances. It should be noted that the quoted or described events may be positive or negative but they are considered appropriate as long they satisfy the framing need of the speaker.

Wodak \& Meyer (2001) described Mitigation strategy as focusing on the locutionary force employed by the speaker. Mitigation strategies equally examine the deployment of language resources to achieve politeness in discourse. It is an attempt to mitigate the force of discriminatory or weighty utterances. Caffy (2006, p. 246) described mitigation as adiscourse strategy in which speakers attenuate one or more aspects of their speech. In mitigation, something which is somehow expected, is substituted, sidestepped, disguised, or simply deleted and left unsaid by the speaker, out of manners, cautiousness, or modesty: it is up to the hearer to reconstruct it inferentially.

The modern world is characterised by struggles, a collapse in spatial difference, discriminations and various ideological conflicts among different groups (Hall 1996). These differences are manifested in a steady rise in societal maladies including nationalism and xenophobia Wodak and Meyer (2001, p. 720). As a result of this, it becomes important to carry out an examination of communicative acts which shaped human actions and inactions with the intention of providing an understanding of the strategies deployed by these participants in passing their messages across.

\section{Methodology}

Many African countries were caught in the South African xenophobic incident. The study focuses on the comments of Nigerian and South African participants because the two countries were at the centre of the xenophobic attacks. As a result of this, various state actors have been involved as discourse participants who will make various evaluations either for or against the phenomenon. Predication as a discourse strategy presents an attempt to review a particular situation and explain the various factors around it.

This study utilises excerpts extracted from the discourse of political state actors in Nigeria and South Africa. This is because the speakers are discourse authors whose language unites or divides the people. The data were extracted from online news sources. The samples were purposively selected from a pool of news items that were published online between the 19th of August and 20th of September 2019. The samples were purposively selected during this period because the season was characterised by diplomatic tension between South Africa and some African countries, especially Nigeria, with state actors from the two countries offering various explanations about the attacks. The data choices were informed by the relevance of each of the samples towards achieving the objective of the study. It is also 
instructive that news items published online often reach a larger audience. The utterances of state actors in national issues like the subject matter of this article often determine the intensity of national issues. The samples were downloaded from the online news platform of The Punch, Vanguard, Tribune, The Nation, Premium Times, Daily Post and The Cable. The news media were selected because they offer a rich avenue for state actors to express their views on socially sensitive issues. The analytical framework for this study is Critical Discourse Analysis. This framework is considered appropriate because of its importance in deepening the interrogation and explanation of the roles of language as a defining tool in human affairs, conduct and social processes generally.

\section{Results and Discussion}

This section of the study is designed to present and analyse the data selected for the study. The springboard for the analysis will be the Discourse Historical Approach (DHA) proposed by Ruth Wodak. As a result of this, the analysis will examine the exploration of the discourse strategies of nomination, predication, argumentation, framing and mitigation in the discourse of state actors in the xenophobic incident in South Africa.

\section{Nomination}

The xenophobic discourse which is the source of the data for this study can be tied around certain causal agents. The crisis no doubt features human and institutional participants that are expressed through different nominations either to advance or defend an argument. The following section examines the discourse strategy of nomination as employed by certain state actors in shaping the xenophobic event.

\section{Excerpt 1 (Daily Post Online, 11 Sept 2019)}

I doubt they would try this if Sheu Shagari, Obasanjo or Jonathan were still President or if Gen Murtala Mohammed Gen Obasanjo, Gen Babangida or Gen Sani Abacha were still Head of State.

\section{Excerpt 2 (Daily Post Online, 11 Sept 2019)}

Why am I not surprised? It is only when the father of a house is weak that strangers beat his children and treat them like filth. It is only when the president of a nation is a coward that foreigners butcher his people and treat them like flies.

In the excerpts presented above, the speakers present examples of nominal nomination. This is because every human activity centres round persons, institutions and objects. In the latest xenophobia issue experienced by Nigerians, state actors employ nominal nominations for criticism. In the excerpts, the speaker presents an indirect contrast between the sitting head of state and past heads of state in order to carry out a comparison of the individuals. The speaker in data sample 1 focuses on the expected role of a head of state. Being a former minister in previous governments, it can be argued that the speaker quite understands the role of a head of state in an issue as sensitive as the South African xenophobic occurrence. It should be noted that the xenophobic occurrence in South Africa is one that presented state actors the opportunity to put expression to their political sentiments. It was an opportunity for them to present certain subjective viewpoint. This they do by either direct or indirect positive presentation of self and negative presentation of others. Excerpt one for example, employs proper nouns with concrete reference as an indirect invitation for the people to compare the supposed action of present and past leaders in relation to attacks on their subjects.

The excerpt here is intended to present the president in bad light and sing the praise of his predecessors. The aothor of this data excerpt, being a leading opposition politician employs nomination to call attention to the leadership qualities of the president. The data excerpt is deployed to make Nigerians realise the incompetence of the current holder of the office of the president. Even though the speaker did not mention the name of the sitting president, the excerpt is a direct indictment of the president's ability to protect the interest of Nigerians as observed in excerpt 
2. In this excerpt, the speaker uses certain figures of speech to paint a picture of the Nigerian head of state, the Nigerian people as well as the South African populace. The Nigerian president is described as a father, who being the head of a family, is expected to do everything within his powers to protect his children against either internal or external aggression. The speaker argues that the president has failed in his duties by allowing South Africans who he described as strangers to maltreat Nigerians. He further captures the degree of the maltreatment of Nigerians by using the nominal expression 'filth' and the verb 'butcher' to paint a gory picture of the extent of their suffering. The speaker equally voiced his low perception of the president's leadership abilities with the adjective 'weak'. This lexical item presents the president as unable to rise to the defence of his people and appears to fold his hands while other nationals kill and maim his people.

\section{Excerpt 3 (Daily Post Online, 11 Sept 2019)}

We can't stop the xenophobic attacks. The truth is that we are an angry nation. What is happening cannot be prevented by any government

Excerpt three also employs nomination to present a picture or nature of xenophobia. It is noteworthy that the social malady of xenophobia is precipitated by anger against foreigners. The speaker of the excerpt under study confirms the opinion that xenophobia is built on anger and that the two cannot be separated. The excerpt deploys referential lexical items that capture the talking point(s) of the situational context of the discourse under review. First and foremost, the speaker understands the fact that certain proactive measures are expected of the government as obligations towards the people; foreigners inclusive. The speaker in the excerpt above presents a picture of someone who is not sensitive to the plight of Nigerians and other foreign nationals who were the target of the xenophobic upheavals. The utterance in excerpt 3 employs attributive nomination in showing the negative tendencies of South Africans as well as the inability of the South African government to stem the tides of the attack. The speaker here is a state actor who is saddled with the responsibility of protecting lives and properties of everyone in South Africa irrespective of their nationality.

\section{Predication}

As stated earlier, predication is a discourse strategy that employs nomination as a means to an end. It is often employed to enhance self and a negatively represent the other party. The major objective of predication is to draw public sympathy to self and attract condemnation to others. Like every social occurrence, the xenophobic attacks involved various situational evaluations with the aim of attracting justification to self and criticism to others. Instances of predication in the various discourses that trailed the xenophobic attack are presented here.

\section{Excerpt 4 (The Nation Online, 5 Sept 2019)}

Over the past few days, our country has been deeply traumatised and troubled by acts of violence. High unemployment and widespread poverty have been cited as possible triggers for the recent disturbances and attacks on immigrants, but some officials say the riots might be the work of criminal syndicates.

\section{Excerpt 5 (Daily Post Online, 11 Sept 2019)}

We decimated your white Boar masters in the killing grounds of Zimbabwe, Namibia, Angola and Mozambique when you were still their slaves. We fought them and their surrogates in the field of battle for your sake and in the end we prevailed and you gained your freedom

\section{Excerpt 6 (3 Sept 2019)}

The South African judicial system is very lenient with certain types of crimes, so if somebody commits a crime now, the system will grant him bail immediately.

The samples identified here are attempts to further evaluate the xenophobic occurrence from different perspectives. Excerpt 4 
presented above is credited to a major South African state actor, in the person of the president of South Africa. The excerpt employs nomination as a predicative tool by deploying certain lexical choices that foreshadow what xenophobia entails in its entirety. For example, in sample 4, lexical choices like traumatised, violence, unemployment, widespread poverty and attacks all combine to capture an event that is completely negative, and inhuman. The data presented here indirectly acknowledges the fact that the South Africans are complicit in the attack. As the leader of the government of the day, the speaker admits that his administration is deeply pained by the acts of violence that had trailed the attacks. This however did not in any way absolve his government of the immediate cause of the xenophobic attack. As observed in the excerpt, "high unemployment and widespread poverty have been cited as possible triggers for the recent disturbances and attacks on immigrants." The utterance is expected to justify the attack by providing a discourse justification for the actions of the irate South African youth. Apart from citing unemployment as the reason for the attack, the speaker goes on to blame the xenophobic outbreak on certain criminals who may be out to cause trouble for his government. On a general note, the excerpt identified here is the attempt of the speaker to attract justification to his government.

In excerpt 5, the speaker presents an historical perspective to the discourse on the xenophobic fracas. The speaker makes a linguistic attempt to describe the addressee as having benefited from the large heartedness of Nigeria in the past. It is an indirect discourse pattern where effort is made, with the instrument of communication, to interrogate the historical background of discourse participants in order to present a negative picture of the addressee and portray the speaker in a very positive image. In the excerpt under analysis, the speaker, apart from presenting a fact of history, indirectly draws the attention of both the addressee and the reading public to the ability of Nigeria and Nigerians to defend themselves in the xenophobic incident. This is done by reminding the addressee of the exploits of Nigeria and Nigerians against external aggression all in a bid to liberate South Africa and South Africans from the bondage of apartheid.

Excerpt 6 is an excerpt of the comment of the representative of the Nigerian government in South Africa. The excerpt is a clear attempt to call out the South African government nay the failure of the South African judicial system in curtailing the criminal tendencies of South Africans. The data sample is the speaker's attempt to advance a reason for the continuous xenophobic attacks. The identified complacency clearly presents the government of South Africa and the judiciary as accomplices by allowing criminals to walk the streets free.

\section{Framing}

Framing as a discourse strategy employs a methodological presentation of a situation from the perspective of the speaker. In this strategy, the speaker identifies a topic from which arguments are generated for or against a viewpoint. The following data excerpts exemplify various instances of framing.

\section{Excerpt 7 (The Nation Online, 6 Sept 2019).}

Nigerians are harming our young people. I would appreciate if the Nigerian security agencies would help us to address this belief and the reality that there are many persons from Nigeria dealing in drugs in our country.

Framing as stated earlier, is another attempt to link certain occurrences with contextual situations. The first lexical item in excerpt 7 Nigerians immediately draws attention to the fact that the Nigerian citizens will be the topic for the argument to be advanced here. It is therefore instructive to note that the succeeding lexical choices as well as the sentences did not deviate from this objective. In the excerpt under review, the speaker advances an argument which identifies insecurity in Nigeria as being remotely responsible for the xenophobic attacks. Being an expert in international relations between the two countries, the speaker is in a vantage position to comment on 
the perceived happenings in Nigeria that may be affecting South Africa and South Africans. The central topic in excerpt 7 is insecurity. This speaker is of the opinion that insecurity in Nigeria is responsible for the xenophobic outbreak. The data excerpt is an attempt to negatively present Nigeria and her security apparatus. Excerpt 6 is made up of three sentences with a pattern of progression typical of an argument. This is observed in the opening sentence that claims that young South Africans are exposed to danger from Nigerians. The second and third sentences are a direct invitation to the Nigerian security agencies to address the concern of South Africa by being more alive to their responsibilities and ensure adequate security of citizens' lives and properties. There is also evidence that the author of the text is indicating the fact that the Nigerian government is not alive to its responsibilities. This can be seen in the following excerpt.

\section{Excerpt 8 (The Nation Online, 6 Sept 2019).}

I believe that Nigerian nationals are involved in human trafficking and other abusive practices. This kind of assistance of ensuring that such persons do not come to our country will be of great assistance to our nation.

Like the first excerpt, this is a also a personal perspective against Nigerians that is introduced by stating a personal belief which accuses Nigerians of human trafficking and other abusive practices. Like the first sample, the second excerpt is designed to negatively present others and positively present self. The speaker presents his view of the source and causes of the attacks from the South African perspective.

\section{Excerpt 9 (Punch Online, 7 Sept)}

We are on high alert monitoring the violence that erupted in the week leading to the death of foreigners and destruction of their properties...we arrested more suspects who had been looting shops in the Guateng province... seventy-four (74) persons were arrested in Katlehong on
Thursday bringing the total number of arrests since the violence broke out to 497.

In excerpt nine, the speaker presents numerical evidences to support the argument advanced. The xenophobic attack is believed to have been allowed to fester as a result of the uncaring attitude of the South African authorities. The excerpt under consideration however seeks to counter this believe. The speaker provides an argument that immediately agrees that foreigners had been attacked and have had their properties destroyed. The second statement in the excerpt is an effort to present the South African police as proactive and alive to its responsibilities compared with the excerpt in samples seven and eight where the speaker presented the Nigerian government as having failed in its duty to ensure adherence to immigration laws. The author of the excerpt then supports her claim by providing concrete evidence in terms of numbers: 74 persons were arrested in Katlehong on Thursday bringing the total number of arrests since the violence broke out to 497 .

While the South African government is making efforts to prove its pro-activeness in the xenophobic outbreak, its Nigerian counterpart also sets out to assure its citizens of the fact that justice will be served. The following excerpt captures this viewpoint.

\section{Excerpt 10 (Punch Online, 7 Sept)}

Let no one be left in any doubt, we will seek and we will obtain by whatever means available, due compensation for all that had been lost. We are committed to a sustained and special effort to see that the ends of justice are met for all our people who have suffered. We have heard the cries of our citizens, and we have witnessed their devastation. We will mourn for the dead and cry for the lost, but we will not stop there.

Like text nine, this sample focuses on action. In other words, it explores the theme of action in advancing its argument. In order to make the argument more explicit, the author employs the second person plural pronoun. This lexical choice produces a sense of 
inclusion in the mind of the addressees. It is noteworthy that many Nigerians had suffered huge material losses, with properties worth millions of money either lost, stolen or vandalised. In the aftermath, the Nigerian government had requested for compensation for its citizens while the South African government had not been positively inclined towards granting the compensation. The use of the verb 'witnessed' as used in the sample presents the speaker as having first-hand information regarding the loss suffered by the Nigerian victims of the xenophobic attack. The excerpt therefore can be described as the evidence that the author identifies with the grievances of Nigerians and seeks to assure them that appropriate action.

\section{Argumentation}

Argumentation is a discourse strategy where the speaker tries to argue for the truthfulness or otherwise of certain viewpoints. It is an attempt to provide justification for beliefs that a speaker has. For Ademilokun (2018, p. 152) arguments are often built around topics from where general ideas are generated to advance the course of the argument. Examples are given below.

\section{Excerpt 11 (Daily Post Online, 11 Sept 2019).}

If anyone still thinks that the ruling ANC party, the SA government and President Cyril Ramaphosa himself are not complicit in this matter then that person is plain dumb.

\section{Excerpt 12 (Vanguard Online, 18 Sept 2019)}

To make meaningful progress, Africans must be encouraged to treat one another as brothers and sisters, in love and unity... building peace is a task for every one of us... it is a seed we plant and nurture for it to grow and bear fruits in our families, countries and the world at large.

The excerpt presented above expresses the author's view about the role of the South African president and his government in the xenophobic outbreak. The general belief, especially among Nigerians and other foreign nationals in South Africa is that the government did not do enough to check the destructive tendencies of the rampaging South African attackers. The excerpt under analysis is a single sentence utterance. The sentence structure in this excerpt is compound complex sentence. In the selected data, the speaker cast aspersion on the person of the South African president. This is achieved by direct reference. Being the centre of the argument, the president is indirectly described as not living up to his responsibilities. The failure of the president can also be described as the failure of his government.

In excerpt 12, the speaker selects admonition as the discourse topic. The excerpt is a reminder of the fact that xenophobia as a social ill signifies the complete breakdown of sanity, law and order. This means that peace becomes a mirage. In the light of this, the author admonishes on the need for people to relate embrace. The text is loaded with lexical items that explain the author's view on the nature of peace in South Africa. Words in this category are nouns and pronouns which include meaningful progress, brothers, sisters, love, unity, etc. Peace as a necessity for human existence is described as a seed that requires constant nurturing. Other excerpts equally acknowledge the opinion that the xenophobic occurrence is a resultant effect of the breakdown of peace. Consider the following excerpt.

\section{Excerpt 13 (Tribune Online, Sept 5, 2019)}

This attack is a shame on the black people, we all need to come together and see ourselves as one. We must erase the ongoing xenophobic killings in Africa, we only have artificial boundaries. We are all the same whether Nigeria or South Africa. We must not also forget so soon that Nigeria helped SA to fight the apartheid regime that helped her to becoming a democratic country in 1994. The attack on one another is mere ignorance and unacceptable.

The author of excerpt 13 is a foremost traditional ruler who also employs the topic of 
history, unity and admonition in advancing the subject matter for the expression of his perspective. The text explains the need for unity which requires Africans to come together and live with one another in peace. Unity as presented in this excerpt ensures that the entire African race sees one another as one indivisible group without physical, social or economic boundaries. Just as observed in excerpt five, the example under analysis also draw its argumentative basis from history. This is seen in the allusion to the historical role played by Nigeria in the fight to liberate South Africa from the shackles of apartheid. The author thus seems to expect the people of South Africa to always call to mind the good deed done to them both by Nigeria and Nigerians and repay those good deeds with brotherly love.

\section{Mitigation}

Mitigation is a discourse strategy that is used in order to intensify or reduce the force of an expression. Ademilokun (2018, p. 163) quoting Huddleston (2002, p. 54) concluded that expressions that have deontic meaning are often used to influence actions and situations. Framing as a strategy is informed by the need for discourse politeness. In the words of Brown and Levinson (1987), discourse politeness is the identification of the fact that certain use of language may hurt our addressees. It therefore requires the infusion of lexical items meant to slightly modify the weight of an expression. Few examples identified in the samples selected for this study are presented here.

\section{Excerpt 14 (The Nation, 5 Sept 2019)}

The Nigerian government must go ahead to press for compensation on the attacks and destruction of the businesses of Nigerians in South Africa.

\section{Excerpt 15}

To make meaningful progress, Africans must be encouraged to treat one another as brothers and sisters...

The deployment of the modal auxiliary verb 'must' as observed in the excerpts presented above intensifies the opinion advanced in the text. In excerpt fourteen for example, it is employed to further emphasise the urgency attached to the opinion of the author that the government of Nigeria should be willing to yield to the yearnings of the people. In the excerpt, the author sends a strong message to the government of Nigeria regarding the monumental loss suffered by Nigerians in the attack. In excerpt fifteen, the adjective 'meaningful' and the modal auxiliary verb 'must' both combine to show that the cooperation needed to drive development is lacking in Africa and among Africans. Africa should not only think of progress but should think of real progress that is characterised by sincere brotherliness. Other parts of speech that serve the purpose of discourse mitigation are presented in the following excerpts.

\section{Excerpt 16}

We call for immediate suspension of the South African business outfits and their activities in Nigeria as we may not guarantee their safety in the old eastern region of Nigeria.

\section{Excerpt 17}

The ohanaeze Ndigbo Youth Council Worldwide advised Nigerians in South Africa to defend themselves or come back home.

In excerpt sixteen, the author employs the time adjective 'immediate' to also show the urgency required of the Nigerian government to move against South Africa. The use of the verb 'advised' in the second excerpt serves to lighten the threat that may be contained in the utterance. The excerpt is a request that could threaten the self-esteem of the party to whom the advice is directed. The excerpt is issued by a cultural pressure group and if the lexical item 'command' had been used, the addressee might have felt insulted. A call like this is important and understandable because the period under study was characterised by calls on the government by different groups for various reasons. The verb serves the purpose of introducing mildness into what could have been a harsh request. 


\section{Conclusion}

This study has explored the discourse strategies employed by state actors in relation to the xenophobic attack against foreigners in South Africa. The study is hinged on the believe that at a period like this in world history, an event like the recent xenophobia in South Africa will affect international cooperation among the two economic powerhouses of Africa. It is equally believed that the event will provide a platform for state actors from the countries to voice their opinion. An examination of the discourse strategies employed in the study revealed that events like the xenophobic attack cannot be completely separated from politics. This is because as observed in the study, state actors explore the provisions of language and the situational context provided by the attacks to create discourse situations required to foster mutual co-habitation.

The choice of the Discourse Historical Approach (DHA) to the study of critical discourse analysis as proposed by Ruth Wodak informed the need to carry out the analysis using the discursive yardsticks of nomination, predication, argumentation, framing and mitigation as outlined by the model. Because the subject matter of the study involved two countries, the instances of nomination observed in the study were used to refer to individuals and groups who had one role or the other to play either before, during or after the xenophobic malaise. In terms of the argumentative pattern of the discourse, the study identified two important discourse features. The study established that different state actors from each of the countries under scrutiny engage in positive self and negative others presentation. This showed that from their discourses, it can be deduced that the state actors were all out to launder the image of their respective countries on the one hand and that of the kith and kin on the other hand. Secondly, the study showed that Nigerian state actors draw more from the fact of history by reminding the South African people and their government of the terror of their past experiences inflicted through apartheid as well as the role played by Nigeria in their liberation. This finding further reinforces the argument that for a people to make progress politically, economically and socially, there is always the need to evaluate and re-evaluate their past. The use of the mitigation discourse strategy as observed in the study finally revealed the fact that the state actors identified the need to curtail the spread of a social ill like xenophobia and bring ensure that its perpetrators are made to answer to justice.

\section{References}

Ademilokun, M. A. (2018) Discursive construction of Nigeria's economic crisis in the media texts of state actors (20162017) Obitun Journal of the Humanities: Ekiti State University, 9, 148-165.

Amossy R. (2018) Understanding Political Issues through Argumentation Analysis in Wodak, R. \& Forchtner, B. The Routledge Handbook of Language and Politics. New York: Routledge.

Arthemis, A. \& Monika, R. (2010) The syntax of nominalisations across languages and frameworks. Berlin: De Gruyter Mouton.

Brown, Penelope and Levinson, Stephen (1987) Politeness: Some Universals in Language use. Cambridge: Cambridge University Press.

Caffy, C. (2006) Mitigation. Edinburgh: Elsevier Ltd.

Fairclough, N. \& Wodak, R. (1997). Critical discourse analysis. T.Van Dijk (ed.), Discourse Studies. A Multidisciplinary Introduction, 2, 258-84. London: Sage.

Gee, J. (2005) An Introduction to Discourse analysis. New York: Routledge

Gumperz, J. (1982) Studies in Interactional Sociolinguistics: Discourse Strategies. Cambridge: Cambridge University Press.

Halliday, M. A. K. \& Hasan, R. (1989) Language, context and text: Aspects of language in a 
social semiotic perspective. Oxford: Oxford University Press.

Harris, B. (2000). Xenophobia: A new pathology for a new South Africa. In Hook, D. \& Eagle, G. (eds) Psychopathology and Social Prejudice. Cape Town: University of Cape Town Press.

Joseph, J. (2006) Identity and Language. Edinburgh: Elsevier Ltd.

Kollapan, J. (1999). Xenophobia in South Africa: The challenge to forced migration. Unpublished seminar proceedings, 7 October. Graduate School: University of the Witwatersrand.

Van-Leeuwen, T. (2006) Critical Discourse Analysis. Cambridge: Elsevier Limited.

Morris, A. (1998). 'Our fellow Africans make our lives hell': The lives of Congolese and Nigerians living in Johannesburg. Ethnic and Racial Studies, 21 (6), 1116-1136.

van Dijk, T. (1997) Discourse Studies. A Multidisciplinary Introduction. London: Sage.

van Dijk, T. (2002) Multidisciplinary Critical Discourse Analysis: A Plea for Diversity. In Wodak, R \& Meyer, M. (ed) Methods of Critical Discourse Analysis, 95-180. London: Sage.

Wodak, R. \& Meyer, M. (2001). Methods of Critical Discourse Analysis. London: Sage Publications. 